\title{
Crosstalk between autophagy and proteasome protein degradation systems: possible implications for cancer therapy
}

\author{
Slawomir Wojcik
}

Department of Anatomy and Neurobiology, Medical University of Gdansk, Gdansk, Poland

\begin{abstract}
The Ubiquitin-Proteasomes System (UPS) and autophagy, two main intracellular protein degradation pathways within the eukaryotic cells which were originally regarded as rather independent, seem to be very closely related. Proteasome inhibitors, including the multipathway inhibitor bortezomib, are drawing increased attention for their therapeutic potential in the treatment of chronic inflammation and cancer, especially tumours with a high degree of malignancy. The over-activation of autophagy induces cell death and may act as a powerful tumour-suppressing mechanism. However, autophagy, serving as an important mechanism to generate nutrients in time of cellular stresses, may directly contribute to the survival of cells treated with proteasome inhibitors, and in consequence, may decrease the effectiveness of therapy. Results of studies performed on several cancer cell lines demonstrated synergy between proteasome inhibitors and autophagy inhibitors. Those results became the base for ongoing clinical trials investigating autophagy inhibition in combination with anti-cancer therapies, including bortezomib. This review provides summary of the latest data on the functioning of the UPS and the mechanisms of autophagy. The new insights describing the main pathways of autophagy activation in response to UPS inhibition related to: (i) Unfolded Protein Response, (ii) PI3K/Akt/mTOR pathway, and (iii) formation of aggresomes, are discussed. It is concluded that concomitant inhibition of the two main cellular protein degradation systems may provide new therapeutic modalities for cancer treatment. (Folia Histochemica et Cytobiologica 2013, Vol. 51, No. 4, 249-264)
\end{abstract}

Key words: autophagy; Ubiquitin-Proteasomes System; proteasome inhibitors; cancer; Unfolded Protein Response; mTOR; LC3; ATF4; aggresomes

\begin{abstract}
Abbreviations
4E-BP1 - eukaryotic initiation factor 4E-binding protein 1; ALLN - Acetyl leucyl-leucyl-norleucinal (also known as N-acetyl-leucyl-leucyl-norleucinal); AMPK $\alpha 1$ - AMP-activated protein kinase $\alpha 1$ subunit; ATF4 - Activating Transcription Factor 4; ATF6 activating transcription factor 6; Atg - autophagy-related proteins; BAG3 - Bcl-2 associated athanogene 3; CRLs - cullin-containing RING-finger ligases; eIF2 $\alpha$

Correspondence address: S. Wojcik, Department

of Anatomy and Neurobiology, Medical University of Gdansk

Debinki St. 1, 80-210 Gdansk, Poland

tel.: +48 5834914 02; fax: +48 5834914 21;

e-mail: swoj@gumed.edu.pl
\end{abstract}

— eukaryotic initiation factor 2; ERK1/2 - extracellular signal-regulated kinase 1 and 2; HDAC6 - tubulin deacetylase histone deacetylase 6; HECT - homologous to E6-associated protein carboxy terminus; $\mathbf{H I F}$ hypoxia inducible factor; HIF-1 $\alpha$ - hypoxia-inducible factor- $1 \alpha$; HSF1 - heat-shock factor $1 ;$ HSP70 - heat shock protein70; HSP90 — heat shock protein90; IRE1 — inositol-requiring kinase 1; JNK - c-Jun $\mathrm{NH}_{2}$-terminal kinase; LC3 - microtubule-associated protein light chain 3; LC3-I (LC3A) - C-terminally cleaved LC3; LC3-II (LC3B) - phosphatidylethanolamine conjugated form of LC3-I; MAPK - mitogen-activated protein kinase; MEFs - murine embryonic fibroblasts; MEK1/2 - MAPK kinase 1 and 2; mTOR - mammalian target of rapamycin; mTORC1 - mTOR complex 1; mTORC2 - mTOR complex 2; NBR1 — neighbour 
of BRCA1 gene 1 protein; p70S6K - p70S6 kinase; PDK1 - 3-phosphoinositide-dependent protein kinase-1; PERK - ER-resident protein kinase; PGPH activity — peptidyl-glutamyl peptide-hydrolysing-like activity; PI3K III - phosphatidyl inositol 3-phosphate kinase class III; RING - really interesting new gene; SESN2 - sestrin-2; TSC2 - tuberous sclerosis2; Ulk1/2 - Unc51-like Ser/Thr kinases 1 and 2; UPR — unfolded protein response; UPS - Ubiquitin-Proteasomes System; UVRAG - ultraviolet irradiation resistance-associated gene; VHL — von Hippel-Lindau tumour suppressor protein

Within the eukaryotic cell there are two main intracellular protein degradation pathways: the Ubiquitin-Proteasomes System (UPS) and autophagy. Intracellular protein degradation processes have gained researcher's attention quite recently, since it has been shown that they play pivotal roles in the regulation of many cellular activities, including the cell cycle, cell differentiation and apoptosis. Moreover, clinical data suggested the existence of close relationships indicating a close connection between UPS, autophagy and pathogenesis of many diseases. Both UPS and autophagy are involved in modification of the course of inflammatory processes, and they are also considered to be important factors which can facilitate cancer treatment. The malfunction in clearance of misfolded or aggregated proteins from the cytoplasm of nerve and glial cells seems to be an especially common pathogenic event in a variety of neurodegenerative disorders. Despite increasing knowledge about both the UPS and autophagy, and the effects caused by their inhibition, information on the interactions of these two systems is still fragmented. The subject of this review article is a summary of the latest information on (1) the functioning of the UPS, (2) the mechanisms of autophagy and (3) pathways of autophagy activation in response to the UPS inhibition.

\section{Proteasomal degradation pathway}

Commonly found in eukaryotic cells, the Ubiquitin -Proteasomes System (UPS) is responsible for the degradation of redundant or abnormal (e.g. unfolded or misfolded) short-lived proteins [1]. The protein degradation performed through UPS is a multistage process which occurs in the presence of ubiquitin, three classes of enzymes and proteasome.

In the initial stage the protein substrate to be degraded binds to ubiquitin. Ubiquitin is a short 76-amino acid long, highly conserved protein (ubiquitin in humans and yeast differs by only three amino acid residues). The attachment of single molecule of ubiquitin to a substrate's lysine to form an isopeptide bond, results in substrate monoubiquitination. Protein substrates can be also ubiquitinated on numerous lysines, resulting in their multiubiquitination [2]. In addition, lysines on the substrate-conjugated ubiquitin may be utilized, to catalyse further cycles of ubiquitination, resulting in substrate's polyubiquitination $[2,3]$. Although ubiquitin molecule contains seven lysines, it is known that the attachment of a polyubiquitin chain to a target protein is mediated only by ubiquitin lysine residue 48 , leading to the degradation of a target protein [4]. Monoubiquitination, multiubiquitination and polyubiquitination moderated by ubiquitin's lysine residues other than residue 48 usually results in regulatory functions (e.g. in: protein transport between the nucleus and cytoplasm, DNA repair and gene expression, kinase activation, DNA damage tolerance, signal transduction and endocytosis) $[3,5]$.

The molecular mechanisms of enzymatic degradation by UPS has been thoroughly describe $[1,3,4$, 6-11]. In short successive action of three enzymes, symbolically called E1, E2, and E3, is necessary to the proper polyubiquitination of the substrate being degraded. The first step (Figure 1.1) of the degradation process mediated by UPS is an establishment of a strong bond between glycine at the C-terminus of ubiquitin and the cysteine of the active site of the enzyme E1 (ubiquitin activating enzyme). To establish this connection, energy from ATP hydrolysis is required. Then (Figure 1.2), as an activated ubiquitin is transferred to the E2 enzyme (ubiquitin-conjugating enzyme), complex E2 enzyme-activated ubiquitin interacts with the specific enzyme E3 (ubiquitin ligase) to transfer ubiquitin into the specific substrate (Figure 1.3). In contrast to a presence of a single E1 enzyme in eukaryotic cells multiple E2 and E3 enzymes form pairs to provide the specificity required to regulate selective protein degradation [7]. The E3, which may be a multi-protein complex, is, in general, responsible for targeting ubiquitination to specific substrate proteins. Because of the great number of distinct protein classes and individual proteins whose proteasomal degradation must be securely controlled, the number of existing E3 ubiquitin ligases has to be high, and, indeed the number of known E3 enzymes exceeds one thousand $[5,7,11]$. The classification of ubiquitin ligases is based on their biochemical and structural features. The best known subclasses include: HECT (homologous to E6-associated protein carboxy terminus), RING-fingers (RING, really interesting new gene) and U-box domains (a modified RING motif without the full complement of $\mathrm{Zn}^{2+}$-binding ligands). 


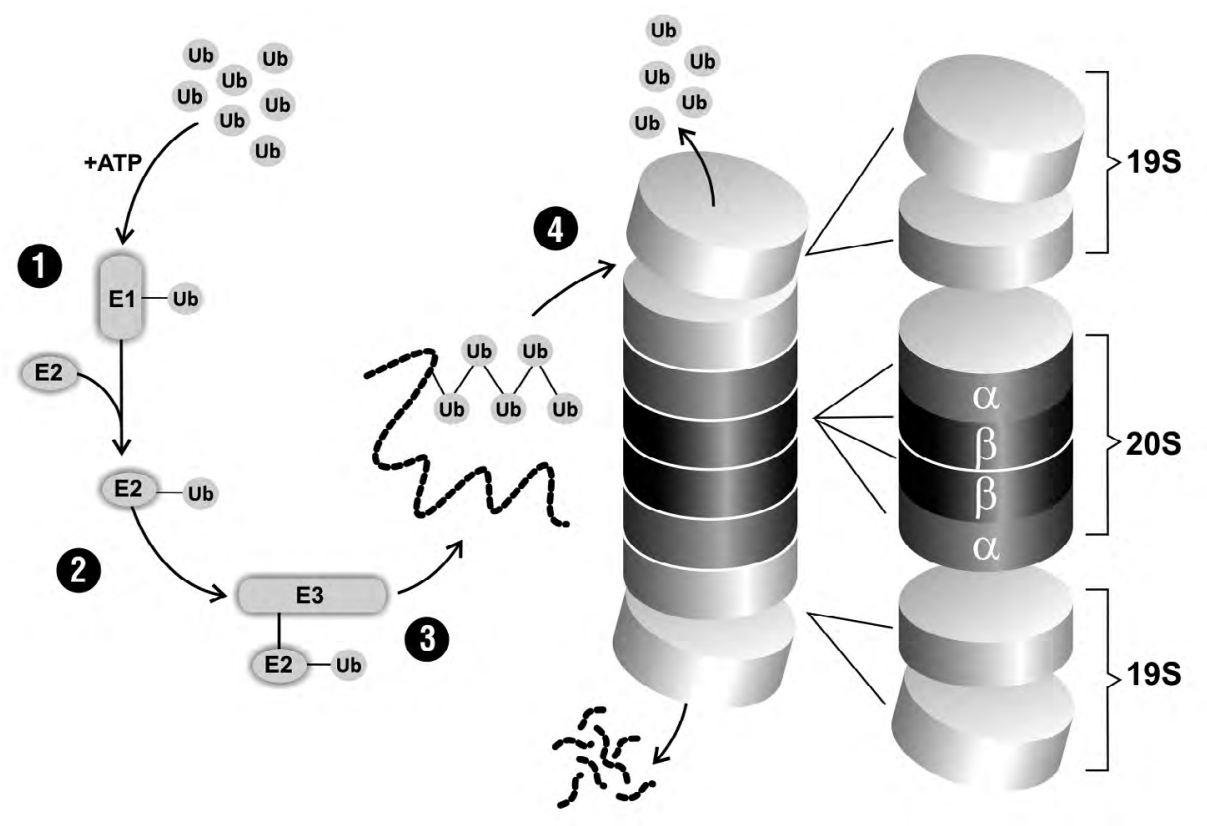

Figure 1. Schematic diagram of the Ubiquitin-Proteasome System. The first step (Figure 1.1) of the degradation process is an establishment of a strong bond between ubiquitin and enzyme E1 (ubiquitin activating enzyme) which requires energy from ATP hydrolysis is required. Then (Figure 1.2), as an activated ubiquitin is transferred to the E2 enzyme (ubiquitin-conjugating enzyme), complex E2 enzyme-activated ubiquitin interacts with the specific enzyme E3 (ubiquitin ligase) to transfer ubiquitin on the specific substrate (Figure 1.3). Properly recognized substrates subsequently undergo numerous rounds of ubiquitination which results in poliubiquitinated proteins that can be further processed by the proteasome (Figure 1.4). The proteasome is composed of three subunits: the main part multi-enzymatic core (20S-unit), responsible for the degradation of the compounds, and two additional 19S-unit regulatory caps. The 20S-unit multi catalytic core is composed of four rings: two identical non-catalytic alpha subunit ( $\alpha 1-\alpha 7)$ rings and two identical catalytic beta subunits $(\beta 1-\beta 7)$ rings, forming a special $\alpha \beta \beta \alpha$ arrangement. Detailed description of the processes has been provided in the main text

Within subclass of RING-fingers ubiquitin ligases two main subfamilies can be distinguished: (i) cullin-containing RING-finger ligases (CRLs) and (ii) those in which the RING-finger and substrate binding domains are contained on the same polypeptide [7, 12-14]. Whereas E3 enzymes belonging to the HECT subclass have a direct catalytic role during ubiquitination, the E3 enzymes from subclasses RING and U-box facilitate protein ubiquitination. E3 substrates are recognized by the specific ubiquitin ligases (E3 enzymes) based on their various structural determinants including primary sequence (binding determinant for e.g. MDM2 ubiquitin ligase), post-translational modification, such as phosphorylation (binding determinant for e.g. $\beta \operatorname{TrCP}$ ubiquitin ligase), oxidation, or presence of N-linked high-mannose oligosaccharides (binding determinant for e.g. Fbx2 ubiquitin ligase), and protein folding state (binding determinant for e.g. CHIP ubiquitin ligase) [7, 12-14]. Another very important substrate recognition method by E3 enzymes is an oxygen-sensing mechanism mediated by the action of the von Hippel-Lindau tumour suppressor protein (VHL), E3 ubiquitin ligase of hypoxia inducible factor $[15,16]$. Properly recognized substrates subsequently undergo numerous rounds of ubiquitination which results in poliubiquitinated proteins that can be further process by the proteasome (Figure 1.4).

The final, third stage, is dependent on the proteasome. The proteasome is a proteolytic complex present in both the nucleus and the cytosol. It is composed of three subunits: the main part a hollow cylindrical multi enzymatic core (20S-unit), responsible for the degradation of the compounds [8, 17] - and two additional 19S-unit regulatory caps, sharing the same structure and located at the opposite ends of the 20S-unit (Figure 1.4). The 19S-units are composed of two sub-complexes. The external one is the lid, which is believed to be responsible for the identification of polyubiquitinated compounds assigned for proteasome-mediated degradation and for the removal of ubiquitin tag. The internal sub-complex of 19S-unite, the base, seems to be responsible for denaturation of the substrate via the action of six ATPase subunits. During the last stage of degradation the protein tagged with a polyubiquitinated chain is recognized by the $19 \mathrm{~S}$ proteasome subunit, then the 19S-unit binds and cleaves the polyubiquitin chain of the target protein, thereby directing it into the $20 \mathrm{~S}$ 
catalytic core $[9,17]$. Finally, protein is degraded by the $20 \mathrm{~S}$ proteasome subunit endopeptidases to short 10-12-amino-acid segments. The 20S-unit multi catalytic core is composed of four rings: two identical non-catalytic alpha subunit $(\alpha 1-\alpha 7)$ rings and two identical catalytic beta subunit $(\beta 1-\beta 7)$ rings, forming a special $\alpha \beta \beta \alpha$ arrangement. The catalytic cleavage of peptides is facilitated by three proteolytically active beta subunits, $\beta 1$ (caspase-like or peptidyl-glutamyl peptide-hydrolysing-like (PGPH) activity), $\beta 2$ (trypsin -like activity) and $\beta 5$ (chymotrypsin-like activity). The $\beta 1$ subunit cleaves the peptide bonds at acidic residues, the $\beta 2$ subunit mainly cleaves peptides past basic amino acids and the $\beta 5$ subunit hydrolyses peptide bonds at hydrophobic residues. In all of the three $\beta$-subunits an $\mathrm{N}$-terminal threonine residue (Thr1) is considered to be the catalytically active amino acid [8].

\section{Proteasome inhibitors}

The proper function of the UPS allows degradation not only of structural and constitutive proteins, but also of many regulatory proteins, including those which control biosynthetic pathways and cell cycle as well as transcription factors, proteins encoded by oncogenes and immune response proteins. It was, therefore, the matter of time to design and synthesize different groups of chemicals for proteasome inhibition with a potential use in the treatment of cancer and autoimmune and inflammatory diseases.

The first reported proteasome inhibitors were acetyl leucyl-leucyl-norleucinal (also known as ALLN or N-acetyl-leucyl-leucyl-norleucinal) and leupeptin [18]. A wide variety of both natural and synthetic substances, which inhibit the activity of the proteasome by reversible or irreversible binding to the active site of its 20S catalytic subunit has been discovered (Table 1).

Proteasome inhibitors are divided in specific classes according to their chemical structure and mechanism of inhibition. Covalent inhibitors are mainly electrophilic and react with the catalytic -hydroxyl of Thr1 in the active sites. In result, they either reversibly (majority of peptide aldehydes, peptide boronates, polyphenols and terpenoids) or irreversibly (majority of epoxyketones, peptide vinyl derivatives, $\beta$-Lactones and derivatives) inhibit the proteasome [19-21]. It should be emphasized that many of well-known natural proteasome inhibitors, such as epoxomicin, lactacystin and syringolin A belong to covalent inhibitors. The lack of reactive group in non-covalent inhibitors is often associated with poor specificity and instability [22]. Their interaction with the proteasome active sites occurs via weak bonds (hydrophobic, electrostatic, hydrogen and/or van der Waals) [19]. The actions of proteasome inhibitors are multidirectional including control of cell cycle, regulation of pro- and anti-apoptotic proteins, sensitization to ligand-induced apoptosis, activation of bone morphogenetic protein signalling, and global translational repression (for review see [21]).

Most of known proteasome inhibitors have low specificity, poor metabolic stability and associate with the proteasome in an irreversible way, which limits their therapeutic use. Peptide boronates are considered as the most promising class of proteasome inhibitors for clinical use. The compounds of this class have 1000 times greater potency than the analogues of peptide aldehydes and are highly specific in relation to proteasome. Peptide boronates reversibly inhibit the chymotrypsin-like activity, and dissociate slowly, thus providing a stable inhibition of proteasomal activity $[19,20,23,24]$. Of special clinical significance was the introduction into the cancer treatment the dipeptide boronic acid, bortezomib (PS-341), which reversibly and selectively inhibits the proteasome $[19,21,25,26]$. Lately, two other inhibitors delanzomib and ixazomib have been approved for phase II and III, respectively, of clinical trials [27].

Recently, Qureshi et al. have demonstrated that two compounds present in grapes, blueberries and red wine - resveratrol and pterostilbene - acted as proteasome inhibitors (Table 1), successfully inhibiting all proteasomal enzymatic activities, i.e. caspase-, trypsin-, and chymotrypsin-like [28]. Those compounds, naturally occurring polyphenols, have been intensively studied because of their pleiotropic health benefits, including anti-inflammatory, anti-aging, antioxidant, cardioprotective, and neuroprotective activities $[29,30]$. Due to these properties and their wide distribution throughout the plant kingdom, resveratrol and pterostilbene are considered as potential preventive/therapeutic agents also against cancer. The knowledge about the potential of resveratrol and pterostilbene to inhibit proteasome activity compels to re-evaluate the previously obtained results observed after resveratrol and pterostilbene administration [31-34].

Interestingly, current studies have revealed new aspects of proteasome function in cells, including the process of autophagy and therapeutic usage of proteasome inhibitors in co-treatment in cancer. However, it should be emphasized, that interference in such complex systems as UPS may lead not only to the expected therapeutic effects, but also to unexpected adverse side effects.

\section{Autophagy}

Autophagy is a ubiquitous and evolutionarily highly conserved process for degrading misfolded proteins, 
Table 1. Characterisation of proteasome inhibitors commonly used in experimental and clinical studies

\begin{tabular}{|c|c|c|c|c|c|}
\hline Name & $\begin{array}{l}\text { ChT } \\
\text {-like } \\
\text { activity }\end{array}$ & $\begin{array}{l}\text { T-like } \\
\text { activity }\end{array}$ & $\begin{array}{l}\text { C-like } \\
\text { activity }\end{array}$ & $\begin{array}{l}\text { Type } \\
\text { of inhibition }\end{array}$ & Stage of development \\
\hline \multicolumn{6}{|l|}{ COVALENT INHIBITORS } \\
\hline \multicolumn{6}{|l|}{ Peptide aldehydes } \\
\hline ALLN (Ac-Leu-Leu-Nle-al.; Calpain Inhibitor I) & + & - & + & Reversible & \\
\hline ALLM (Ac-Leu-Leu-Met-al.; Calpain Inhibitor II) & + & - & + & Reversible & \\
\hline MG132 (Z-Leu-Leu-Leu-al) & + & - & + & Reversible & \\
\hline MG115 (Z-Leu-Leu-Nva-al) & + & - & + & Reversible & \\
\hline Z-Leu-Leu-Phe-H & + & - & - & Reversible & \\
\hline Z-Ile-Glu(OtBu)-Ala-Leu-H (PSI) & + & - & + & Reversible & \\
\hline \multicolumn{6}{|l|}{ Peptide boronates } \\
\hline MG262 (Z-Leu-Leu-Leu-B(OH)2 & + & - & + & Reversible & \\
\hline Bortezomib (PS-341) & + & - & $(+)$ & Reversible & FDA-approved (Velacade) \\
\hline Delanzomib (CEP-18770) & + & - & - & Reversible & Phase I II \\
\hline Ixazomib (MLN-2238, MLN-9708) & + & - & - & Reversible & Phase III \\
\hline \multicolumn{6}{|l|}{ Epoxyketones } \\
\hline Epoxomicin & + & $(+)$ & $(+)$ & Irreversible & \\
\hline Carfilzomib (PR-171) & + & - & - & Irreversible & FDA-approved (Kyprolis) \\
\hline Oprozomib (ONX-0912/PR-047) & + & - & - & Reversible & Phase I II \\
\hline \multicolumn{6}{|l|}{ B-lactones and derivatives } \\
\hline Lactacystin & + & + & - & Irreversible & \\
\hline Clasto-Lactacystin beta-lactone & + & + & - & Irreversible & \\
\hline Marizomib (NPI-0052, Salinosporamide A) & + & + & $(+)$ & Irreversible & Phase Ib \\
\hline \multicolumn{6}{|l|}{ Polyphenols } \\
\hline (-)-Epigallocatechin gallate (EGCG) & + & - & - & Reversible & \\
\hline Resveratrol & + & + & + & & \\
\hline Pterostilbene & + & + & + & & \\
\hline \multicolumn{6}{|l|}{ Terpenoids } \\
\hline Pristimerin & + & - & - & Reversible & \\
\hline Celastrol & + & - & - & Reversible & \\
\hline \multicolumn{6}{|l|}{ Peptide vinyl derivatives - Syrbactins } \\
\hline Syringolin A & + & + & + & Irreversible & \\
\hline \multicolumn{6}{|l|}{ NON-COVALENT INHIBITORS } \\
\hline TMC-95 and derivatives & - & - & - & & \\
\hline TMC-95A & + & + & + & Reversible & \\
\hline \multicolumn{6}{|l|}{ Peptides and Pseudopeptides - Natural peptides } \\
\hline Argyrin A & + & + & + & Reversible & \\
\hline Gliotoxin & + & - & - & Reversible & \\
\hline \multicolumn{6}{|l|}{ Non peptide molecules with no electrophilic function } \\
\hline Aclacinomycin A (Aclarubicin) & + & - & - & Reversible & \\
\hline \multicolumn{6}{|l|}{ Bisbibenzyl derivatives } \\
\hline Marchantin M & + & - & + & Reversible & \\
\hline
\end{tabular}

Inhibits ChT-like — chymotrypsin-like; T-like — trypsin-like; C-like — caspase-like activity 
long-lived proteins, macromolecules and damaged or old organelles by encircling them with membrane with a following fusion of the vesicle with lysosomes. In mammalian cells three main types of autophagy have been described (for review see [35, 36]). Microautophagy is a process in which lysosomes directly take up portions of cytoplasm for degradation, whereas in chaperone-mediated autophagy cytoplasmic chaperone proteins recognize and transport soluble proteins to the lysosomes. Macroautophagy (referred here as autophagy, a focus of this review), is a process in which a non-selective sequestration of cytoplasmic material, including organelles, is followed by digestion in lysosomes. Autophagy is considered as a protection process which enables cells to survive adverse conditions like starvation, infections, toxins and other types of cell stress. Autophagy occurs only in the cytoplasm and in most of the cells it is on-going constitutively at a low activity. However, in stressful conditions it may be up-regulated to a high level, providing the cell with nutrients and energy substrates necessary to sustain basic cellular activities. To trigger the acute induction of autophagy signals about extracellular environmental conditions unfavourable for the cell (such as hypoxia or a lack of ATP, necessary nutrients or growth factors) and/or about disturbances in the intracellular environment (such as increased level of mis-/unfolded cytoplasmic proteins or unfolded protein response) are required.

\section{Pathways of autophagy induction}

The autophagy induction is characterized by fast kinetics due to post-translational modifications of many cellular components, including autophagy-related proteins (Atg). The cascade of events linking the variety of autophagy-triggering signals with activation of downstream targets has not been completely elucidated, however, two main pathways controlling autophagy, mTOR-dependent and mTOR-independent, are currently being studied intensively [37]. The latter depends on mTOR-independent activators categorised in different pharmacological classes including calpain inhibitors, type 1 imidazoline receptor (I1R) and voltage-gated sodium channel $\left(\mathrm{Na}_{\mathrm{v}}\right)$ agonists as well as voltage-gated potassium channel $\left(\mathrm{K}_{\mathrm{v}}\right)$ and calcium channel $\left(\mathrm{Ca}_{\mathrm{v}}\right)$ antagonists [37, 38].

The former canonical pathway depends on mammalian target of rapamycin (mTOR), Ser/Thr kinase being the main regulator of autophagy, indicated as a critical regulator of the balance between cell growth and autophagy in response to extracellular stresses and disturbances of intracellular physiological conditions [39]. Within the eukaryotic cells
mTOR is present in the form of at least two distinct multiprotein complexes of different intracellular activity and regulatory capacity. mTOR complex 1 (mTORC1) is responsible for autophagy induction in response to stress, reduced IGF1/insulin signalling, and starvation [39, 40]. During such unfavourable conditions, mTORC1 dissociates from the Ulk1 complex (see below) allowing it to initiate autophagosome formation. In addition to mTOR, the other the main components of the mTORC 1 comprise DEPTOR, raptor, $\mathrm{G} \beta \mathrm{L} / \mathrm{mLst} 8$, FKBP38 and PRAS40 proteins [41, 42]. mTOR complex 2 (mTORC2) is a negative regulator of autophagy under conditions of nutrient depletion [43]. In addition to the core compounds of the mTORC2 such as mTOR, ricor (rapamycin insensitive companion of mTOR), Sin1/MIP and G $\beta \mathrm{L}$ / $/ \mathrm{mLst} 8$, there are also other non-canonical components such as DEPTOR, protor/PRR5, Hsp70, Rac1, Tsc1/2 and Tel2/Tti proteins [44-47].

\section{Autophagy signal transduction and corre- sponding morphological changes}

After activation by appropriate signalling pathways, autophagy proceeds via a series of sequential stages that lead to the formation of several characteristic morphological structures (Figure 2.1) such as phagophore, autophagosome, amphisome and autolysosome in which the targeted substrates become finally degraded by lysosomal hydrolases [37]. Phagophore formation and elongation are the first steps of autophagy. Recently, a double-layered isolation membrane, the omegasome structure localized in endoplasmic reticulum, has been proposed as an origin of the phagophore [48].

The process of formation of active phagophore (nucleation) requires the collective action of a few complexes (Figure 2.1): Atg1 complex, class III PI3K complex (including phosphatidyl inositol 3-phosphate kinase class III defined also as Vps34, core activator of the Vps34 PI3 kinase complex known as Vps15, enhancer of autophagosome formation $\operatorname{Atg} 14$ and Vps30/Atg6 orthologue Beclin1 the core subunits, bcl2-interacting protein), mAtg9/AtgL1 (Atg9 orthologue in mammalian cells), Ambra 1 and UVRAG (Ultraviolet irradiation resistance-associated gene) which is a positive regulator of Vps34-Beclin1 complex [49-56]. Many Atg's have been identified in yeast. Although most of them are conserved in mammals, which is why information about orthologues is usually given, the molecular composition of the Atg1 complex differs between yeast and mammals.

Mammalian autophagy factors of Atg1/Ulk1 complex are Ulk1/2 (Unc51-like Ser/Thr kinases 1 and 2), 


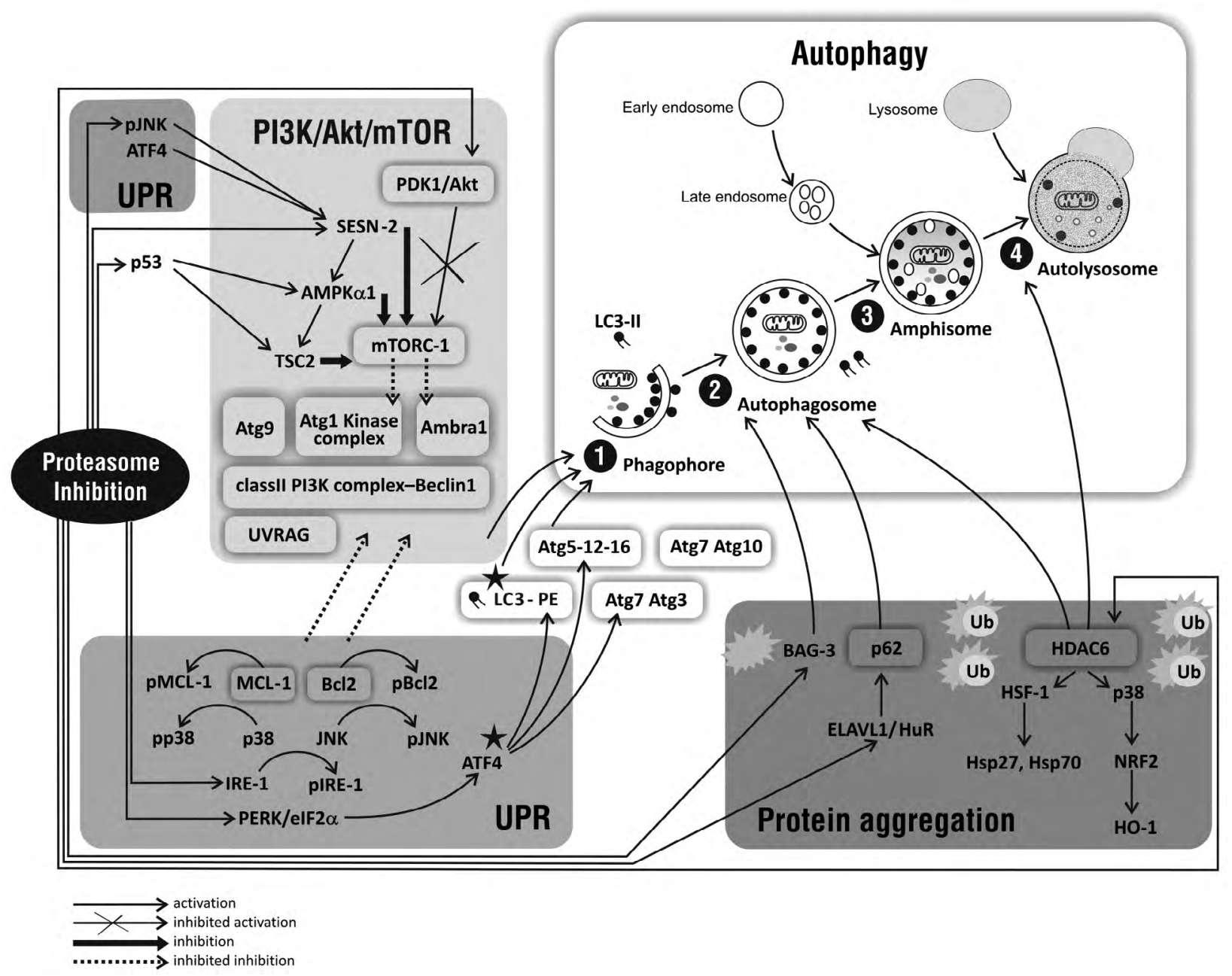

Figure 2. Schematic presentation of molecular mechanisms linking proteasome inhibition to autophagy. Proteasome inhibition leads to the substantial changes in PI3K/Akt/mTOR signalling pathway, triggers unfolded protein response (UPR) and protein aggregation/aggresomes formation. All those events occur during different stages of autophagy: formation of phagophore (Figure 2.1), autophagosome (Figure 2.2), amphisome (Figure 2.3) and, finally, autolysosome (Figure 2.4) where, having become damaged, the substrates are degraded by lysosomal hydrolases. Accumulation of the proteins LC3 and ATF4 due to the impairment of proteasome function has been marked by a star. Detailed description of the processes has been provided in the main text

FIP200 which belongs to the focal adhesion kinase family interacting proteins, mammalian Atg13 and its binding protein, named Atg101 [55-57]. They are responsible for propagation of the signal initiating autophagy via phosphorylation of various substrates. In physiological conditions (no cell starvation) mTORC1 suppresses the phagophore formation by direct interaction with the Ulk1 complex (Ulk1-Atg13-FIP200-Atg101). The mTORC1 phosphorylates and inhibits Ulk1 and its interacting partner Atg13 [58] as well as AMBRA1, the key link between Ulk1 and Beclin-1 complexes (for review see [54]). Moreover, mTORC1 controls WIPI2 (mammalian orthologue of Atg18), which is necessary for phagophore formation, and regulates DAP1, another potent autophagy inhibitor [48, 59]. During conditions of cell starvation mTORC1 releases Ulk1 complex, allowing it to associate with the membrane from which phagophore originates [50].

For the next stage, called expansion/sequestration, two ubiquitin-like conjugation systems are essential. The first one engages the formation of Atg5-12-16 conjugate, mediated subsequently by E1- and E2-like enzymes, Atg7 and Atg10, respectively. The second system engages conjugation of microtubule-associated protein light chain 3 (LC3/Atg8) to the membrane phospholipid phosphatidylethanolamine (PE), the process also controlled by E1- and E2-like enzymes, Atg7 and Atg3, respectively. In human cells there are several cellular forms of LC3: full-length protein LC-3, the C-terminally cleaved protein referred to as LC3-I (LC3A) and the PE-conjugated form of LC3-I 
referred to as LC3-II (LC3B) and LC3 paralog LC3C. During the expansion/sequestration stage, the phagophore enlarges, enwraps portions of cytoplasm with autophagic substrates and closes to form immature autophagosome (Figure 2.2). Once the autophagosome is formed, Atg5-12-16 conjugate is detached and recycled. Also LC3-II from the outer autophagosome membrane is removed, while LC3-II that is attached to the inner membrane - remains [60]. The amount of LC3-II becomes a marker for the formation of autophagosomes. The recent study performed on human cells infected with S. Typhimurium, showed that LC3C was required for antibacterial autophagy because in its absence the remaining ATG8 orthologs did not support efficient autophagy of intracellular bacteria [61]. The subsequent reports indicated that differential involvement of LC3 paralogs, LC3-II and LC3C, can classify autophagy in two separate programs that execute either pro- or anti-tumorigenic activities in renal cell carcinoma cells $[62,63]$.

Amphisome formation, fusion of autophagosome with endosome, the next stage of autophagy, is mediated by specific SNARE proteins and members of the Rab family (Figure 2.3). In this stage proteolytic enzymes from endocytic organelles with lowered $\mathrm{pH}$ to create an acidic milieu of an amphisome content. During the last stage of apoptosis (Figure 2.4), autolysosome formation, amphisome subsequently fuses with lysosome or late endosome to form an autolysosome in which the cytoplasmic cargo is degraded by lysosome hydrolases and degradation products are recycled for the synthesis of new molecules. The mechanisms of autophagosome maturation and subsequent fusion are complicated and have been recently reviewed [64, 65]; since published data do not link those processes directly with proteasome inhibition, they will not be discussed in this review.

\section{Crosstalk between proteasomal system degradation and autophagy pathways}

Large protein aggregates, even ubiquitinated, are excluded from proteasomal degradation, and can be degraded only by autophagy. This process requires autophagosomal membrane receptors like multi-domain scaffold/adaptor protein p62/SQSTM-1, or a neighbour of BRCA1 gene 1 (NBR1) protein [66]. It has been reported that p62 binds non-covalently to the ubiquitin of polyubiquitinated proteins and then polymerises into cytosolic, nuclear and lysosomal aggregates. p62 interacts with LC3 and acts as a bridge connecting ubiquitinated protein aggregates and autophagosomes [67]. Intriguingly, p62/SQSTM1 is also known as an inhibitory factor of proteasomal degradation of LC3 [68].
In linking proteasomal degradation and autophagy an important role is also played by the tubulin deacetylase histone deacetylase 6 (HDAC6), the enzyme that regulates the acetylation of $\alpha$-tubulin and facilitates transport of polyubiquitinated protein aggregates to the nascent phagophore (for review see [69]). HDAC6 has been shown to be involved in both aggresome formation and the fusion of autophagosomes with lysosomes, making it an attractive target to regulate protein aggregation. Recent data shows direct interaction between HDAC6 and p62; moreover, this interaction regulates HDAC6 deacetylase activity [70].

New findings have documented the association between proteasomal degradation and autophagy pathways. It has been shown that pro- and anti-tumorigenetic apoptotic programs are regulated by already mentioned constituent of UPS, von Hippel-Lindau tumour suppressor protein (VHL) which is E3 ubiquitin ligase for hypoxia-inducible factor- $1 \alpha$ (HIF-1 $\alpha$ ) [62, 63]. The VHL inhibits LC3-II-mediated autophagy and, in addition to the inhibition of HIF- $1 \alpha$ protein, induces expression of the LC3C protein. Both VHL's actions contribute to tumour-supressing autophagic activity.

\section{Proteasome inhibition is associated with autophagy}

Proteasome inhibitors (see Table 1; data are based on $[19,20,23,28,71-73])$, including the multipathway inhibitor bortezomib, are drawing increased attention for their therapeutic potential in the treatment of chronic inflammation and cancer, especially tumours with a high degree of malignancy. Inhibition of proteasomal activities used to induce cell death has been previously shown to induce autophagy [74, 75] as well, indicating a coordinated and complementary relationships between these two protein-degradation systems.

\section{Effects of different classes of proteasome inhibitors on autophagy in cancer}

As explained earlier in this review, LC3-II and Beclin-1 proteins are necessary for autophagosome formation and, consequently, are commonly used as markers of autophagy. Increased cellular levels of LC3-II and Beclin-1 proteins were found after bortezomib treatment of human glioblastoma U251 and U87 cells [74], melanoma cells [24], several cell lines of head and neck squamous cell carcinoma [76] and human osteosarcoma (HOS) cells [77]. In human colon cancer HCT116 cells and murine embryonic fibroblasts (MEFs) bortezomib increased 
expression of LC3-II but did not lead to significant changes in Beclin-1 levels [75]. On the contrary, in the thyroid cancer cell line FRO82-1 bortezomib, as well as epoxomicin, increased the expression of LC3-II protein but reduced the protein level of Beclin-1 [78]. Another proteasome inhibitor MG-132, in a time- and dose-dependent manner increased the content of LC3-II in HCT116 cells [75], colon cancer cells HT-29 [79, 80] and SW1116 [80], thyroid cancer cells [78], gastric cancer cells [81], HeLa cells [82], prostate cancer DU145 cells and MEFs [75] and in immortalized dopaminergic neuronal N27 cell line [83]. In the majority of the above-mentioned experimental conditions there were no significant changes in Beclin-1 levels, and in thyroid cancer cells a decrease of Beclin-1 protein level has been reported [78]. An increase of LC3 and LC3-II has been reported also after treatment with NPI-0052, ALLN (N-acetyl-leucyl-leucyl-norleucinal), epoxomicin and lactacystin of human prostate cancer cells [84], HCT116 cells [75], thyroid cancer cells [78], human dopaminergic neuroblastoma SH-SY5Y cells and dopaminergic neurons obtained from UPS-impaired mouse model of Parkinson's disease (PD) $[85,86]$. Differently than in the thyroid cancer cells [78], both in SH-SY5Y cells and in the midbrain of the UPS-impaired mouse model of PD, treatment with lactacystin significantly increased the level of not only LC3-I/II but also Beclin-1 protein, and reduced the levels of p-mTOR and mTOR [85]. Moreover, Marchantin M, a novel proteasome inhibitor tested in prostate cancer cells, significantly induced expression of LC3-I and its further conversion to LC3-II [87].

Activation of autophagy measured by increased expression of LC3, LC3-II and Beclin-1 after the application of resveratrol was observed in a variety of cancer cell lines [32-34, 88]. Pterostilbene also caused a simultaneous increase in the expression of autophagic marker proteins Beclin-1 and/or LC3-II in breast [89, 90], lung [91] and bladder cancer cells [31] as well as in human leukaemia cells [92].

\section{Direct effects of proteasome inhibition on autophagy markers}

Autophagy is a dynamic process, and it is well known that LC3-II is degraded after fusion of autophagosomes with lysosomes $[56,93]$. It was shown that the processing of LC3 occurs via the 20S proteasome. This processing is ubiquitin- and ATP-independent, and both the $\mathrm{N}$-terminal helices and the ubiquitin fold of LC3 are required. The addition of the N-terminal helices of LC3 to the N-terminus of ubiquitin renders ubiquitin susceptible to $20 \mathrm{~S}$ proteasomal activity. Furthermore, the 20S proteasome processes LC3 in a few stages. Initially, it cleaves LC3 within its ubiquitin fold, and this leads to the disruption of the conjugation function of LC3. Finally, in the presence of high amount of active proteasomes, LC3 becomes completely degraded [68]. Therefore, inhibition of proteasome activity may lead to the accumulation of LC3-II proteins (Figure 2). Also, inhibition of autophagic degradation can often lead to the accumulation of LC3-II proteins [94]; however, in all the above-cited papers rapidly activated autophagy after proteasome inhibition was observed [75, 85]. The presence of a considerably increased number of autophagosomes at various stages was postulated as the most convincing proof of active ongoing autophagy after proteasome inhibition by different groups of proteasome inhibitors [24, 88, 91, 95-97].

A study performed on HCT 116 cells showed that proteasome inhibitors (MG-132, lactacystin, ALLN and bortezomib) did not affect the expression level of other proteins important for the autophagy stage of expansion/sequestration, namely Atg5 and Atg7 [75]. On the contrary, in other experimental model, some lines of human prostate cancer cells (LNCaP-Pro5) treated with bortezomib and NPI-0052 showed an increase in Atg5 and Atg7 transcription [84], also treatment with resveratrol increased the level of Atg5 in glioma cells [88].

The influence of proteasome inhibition on autophagy at the stages of amphisome and autolysosome formation has not been yet extensively investigated. Experiments on HCT 116 cells revealed that the co-localization of GFP-LC3 (an autophagosome marker) with Lamp-1 (a lysosome marker) after incubation with MG132, the covalent proteasome inhibitor, was similar to the co-localization of this proteins in untreated control cells. Moreover, it was reported that MG132 did not affect the fusion of autophagosomes with lysosomes [98]. According to another report, treatment with resveratrol, also a covalent proteasome inhibitor, leads to blockade of autolysosome formation, as assessed by the absence of co-localization of LC3 and Lamp-2 [99]. Experimental studies designed to evaluate if non-covalent proteasome inhibitor Marchantin $\mathrm{M}$ has an influence on the fusion process of amphisome and lysosomes, did not show any blockade of autolysosome formation [87]. The main conclusion from those reports is that the effects of proteasome inhibition on mechanisms of autophagosome maturation and fusion are ambiguous, which probably results from the great variety of chemical structures and activities of various proteasome inhibitors. 


\section{The main pathways of autophagy activation in response to UPS inhibition}

\section{Unfolded Protein Response}

To date, several different pathways which explain the activation of autophagy after proteasome inhibition have been described. The best documented is the pathway linking autophagy activation with the response to endoplasmic reticulum (ER) stress disruption of endoplasmic reticulum homeostasis caused by accumulation of misfolded proteins not processed by functionally impaired proteasomes [75]. The unfolded protein response (UPR), also called protective hypoxia-inducible factor (HIF)-independent pathway [100], is considered to be the major compensatory and protective mechanism during ER stress. Among the three known pathways of UPR mediated by (i) ER-resident protein kinase/eukaryotic initiation factor 2 (PERK/eIF2 $\alpha$ ), (ii) activating transcription factor 6 (ATF6), and (iii) inositol-requiring kinase (IRE1), the last one was initially proposed as the most important in proteasome-induced autophagy. IRE1 is responsible for the activation of two well-established mechanisms in mammalian cells. The first one, activation of c-Jun $\mathrm{NH}_{2}$-terminal kinase (JNK), is required for the processes leading to cell death by apoptosis $[101,102]$. The second mechanism involves an alternative splicing of a $X B P-1$ gene transcript, leading to the formation of an active transcription factor that participates in UPR [103, 104]. According to Ding et al. [75], JNK but not XBP-1 seems to be involved in the induction of autophagy after treatment with proteasome inhibitors. In a subsequent study these authors observed that increased autophagy in HOS cells in response to bortezomib corresponded with altered levels of intracellular mitogen-activated protein kinase (MAPK) signalling molecules such as decreased levels of phosphorylated MAPK kinase (MEK1/2) and extracellular signal-regulated kinase (ERK1/2), and simultaneous increase of phosphorylated JNK and p38 MAPK [77]. Also, after exposure of melanoma cells to bortezomib, no changes were observed in the total expression levels of IRE1, ASK1, JNK and $\mathrm{p} 38$, however, this proteasome inhibitor triggered the phosphorylation of these proteins [24]. The link between JNK1 activation via IRE-1-mediated UPR and autophagy induction by proteasome inhibition can be explained in the following way. Active, phosphorylated JNK1 mediates Bcl-2 phosphorylation, Bcl-2 dissociation from Beclin-1 and consequently activates autophagy [105]. A similar effect, however, with the involvement of MCL-1 protein, can be mediated by active $\mathrm{p} 38$, another downstream substrate of IRE-1. Results of several reports showing that proteasome inhibition leads to the induction of the phosphorylation of anti-apoptotic proteins such as $\mathrm{Bcl} 2, \mathrm{Bcl}-\mathrm{xL}$ or MCL-1, and autophagy [24, 76, 106, 107] support the theory that both signal transduction pathways, i.e. JNK1/Bcl-2 and p38/MCL-1 become activated by proteasome inhibitors.

Many studies showed that PERK/eIF2 $\alpha$ canonical signalling pathway, which mediates autophagy during ER stress, may be triggered by proteasome inhibition [87, 108-110]. Studies on Marchantin M-induced, PI3K/Vps34-dependent autophagy revealed that not the IRE1/JNK pathway but the PERK/eIF2 $\alpha$ pathway seemed to be involved in autophagy induction by this proteasome inhibitor [87]. Although activation of the IRE1-mediated pathway of UPR was observed, a downstream effect of this activation was the increase in the spliced form of XBP-1 mRNA, however, the translated protein was found to be not involved in the autophagy induction [87]. In the same study, evaluation of ATF6-mediated pathway showed just a slight increase of ATF6 mRNA.

Activation of the PERK/eIF2 $\alpha$ pathway and phosphorylation of eIF $2 \alpha$ by PERK leads to general inhibition of protein synthesis, but also selectively promotes translation of some proteins, including ATF4 (Activating Transcription Factor 4) (Figure 2). It is in accordance with growing evidence that the transcription factor ATF4 is an important player in proteasome inhibitor-induced autophagy. ATF4 binds to the LC3 promoter under basal and hypoxic conditions to up-regulate the LC3 cellular expression [111] and, in this way, to promote autophagy. The subsequent increases in the transcription of the $A T G 5$ and $A T G 7$ genes in response to the increased ATF4 levels are related to the fact that the promoter regions of $A T G 5 / 7$ contain ATF/CREB binding sites $[84,111]$.

Many data suggest that proteasome inhibitors may significantly increase ATF4 gene expression. After incubation of two human liver tumour cell lines (HepG2 and HA22t/VGH) with MG-132 the level of ATF4 mRNA was enhanced in both cell lines [112]. Bortezomib also caused increased gene expression of $A T F 4$ gene in various cell lines of human multiple myeloma [113] and rats liver cells [114]. In human LNCaP-Pro5, PC3 and PC3-R prostate cancer cell lines and MEFs treated with bortezomib and NPI0052 [84], the eIF $2 \alpha$ phosphorylation-dependent mechanism was at least partially responsible for the increase in ATF4 level after proteasome inhibition. Interestingly, also resveratrol significantly increased ATF4 gene expression in HEK293 cells [115].

It has to be mentioned that the increased level of ATF4 protein observed after proteasome inhi- 
bition [116, 117] may be not only the result of the downstream activity of PERK, but could be also a consequence of the inhibition of its degradation by proteasomes and accumulation within cell (Figure $2)$. It was reported that $\beta \operatorname{TrCP} 1$, a ligand-binding subunit of SCF $/ \beta$-TrCP E3 ubiquitin ligase complex, decreased ATF4 protein level by ubiquitination which lead to its proteasomal degradation [118]. The study of human breast cancer cell lines MCF7 and MDA MB 231 showed that, independently of the upstream activity of PERK, after treatment with bortezomib ATF4 was protected against proteosomal degradation and directly stabilized. These processes resulted in an increase of LC3B cellular level [117].

\section{PI3K/Akt/mTOR}

There is a convincing evidence that the PI3K/Akt/ /mTOR pathway represents the major regulatory mechanism of autophagy. Activity of mTOR is primarily maintained by an active PI3K/Akt kinase pathway, while the AMP-activated protein kinase $\alpha 1$ subunit (AMPK $\alpha 1$ ) acts as the main inhibitor of mTOR activity [119]. Activated mTOR in mTORC1, in addition to inhibition of the membrane targeting of the Ulk1 complex by direct interaction with it, phosphorylates eukaryotic initiation factor $4 \mathrm{E}$-binding protein 1 (4E-BP1) and p70S6 kinase (p70S6K) to increase cap-dependent translation and translation initiation complex formation, respectively [120]. Inhibited mTORC1 disinhibits kinase Ulk1/2 activities, resulting in FIP200 phosphorylation, which is required for the early stages of autophagosome formation [50]. It has been reported that after MG-132 application in various experimental cell culture models [79-81, 121] characteristic features of increased autophagy were accompanied by pronounced inhibition of mTORC1-mediated phosphorylation of 4E-BP1 and S6K. Initially, the mechanism by which proteasome inhibition resulted in the disruption of mTORC1 remained vague, but recent studies using bortezomib as an autophagy inducer showing up-regulation of sestrin-2 (SESN2/Hi95) [122] have shed new light on this problem. SESN2 protects cells against oxidative and genotoxic stresses, and mediates the inhibition of mTOR [123]. Thus, the bortezomib-induced increase of SESN2 level leads to the inhibition of the main regulatory subunits of mTORC1 by a mechanism that requires interaction with AMPK $\alpha 1$ to mediate the phosphorylation of tuberous sclerosis2 (TSC2), an upstream mTOR inhibitor [119].

Moreover, it should be pointed out that SESN2 is a product of the p53 target gene [124]. Significant increase of p53 level in several cancer cell lines has been reported after bortezomib administration [125] and in dopaminergic neurons after lactacystin administration [126]. Lactacystin treatment resulted in the induction of autophagy mediated by p53 but not by the UPR. Several pathways through which increases in p53 are able to up-regulate autophagy in noncancerous cells have been discussed. Among them, activation of AMPK $\alpha 1$ and subsequent inhibition of mTOR have been proposed so far, but involvement of SESN2 also has to be taken into consideration $[49,124]$. However, most cancer cells lack functional $\mathrm{p} 53$, indicating induction of ATF4-mediated [122] or the recently described pJNK-mediated [127] SESN2 expression as an essential factor linking ER stress or proteasome inhibition to mTOR inhibition and autophagy in cancer cells.

The above-mentioned mechanism of AMPK $\alpha 1$ activation, which in turn inhibits mTOR, was also described after incubation of human umbilical vein endothelial cells (HUVECs) with pterostilbene, a naturally occurring polyphenol. Pterostilbene promoted autophagy via a rapid elevation of intracellular calcium concentration and subsequent activation of AMPK $\alpha 1$ [128]. Another form of autophagy induction was observed after cells' treatment with Marchantin M. This proteasome inhibitor decreased mTOR protein levels [85] or inhibited mTOR activators pospho-Akt and 3-phosphoinositide-dependent protein kinase-1 (PDK1) [87]. Pterostilbene-induced autophagy in human lung cancer cell lines, confirmed by the formation of acidic vesicular organelles and LC3-II production, was also mediated by the inhibition of PI3K/Akt [91]. Under these experimental conditions, as well as in resveratrol-induced autophagy in human U373 glioma cells, activation of the Ras/Raf-1/ /mitogen-activated protein kinase 1/2 (MEK1/2)/ /extracellular signal-regulated kinase 1/2 (ERK1/2) pathway has been observed [34]. However, data are still scarce, and the mechanisms linking this pathway with autophagy induced by proteasomal inhibition need further clarification.

\section{Formation of aggresomes}

Proteasome inhibition leads to the accumulation of protein, often polyubiquitinated, which are prone to aggregate and make structures known as 'aggresomes'. Aggresomes are predominantly present in perinuclear compartments, and they are considered to be a place of selective autophagy of damaged proteins that are isolated from other cytoplasmic components [129]. The clearance of polyubiquitinated proteins present in aggresome is mediated by ubiquitin-binding proteins like p62/SQSTM1 (Figure 2). p62/SQSTM1 seems 
to be a connecting link between autophagy and proteasome-mediated proteolysis, and its level strongly increases during exposure to various oxidative agents and proteasomal inhibitors, such as MG-132, lactacystin, epoxomicin and PSI [66, 130-132]. Furthermore, proteasomal inhibition caused by MG-132 leads to accumulation of p62/SQSTM1 bound irreversibly to perinuclear protein aggregates [132]. This phenomenon may be explained, at least partially, on the basis of experiments performed with MG-132 in the ARPE19 cell line [132]. Viiri et al. studied the involvement of ELAVL1/HuR protein in the regulation of p62/ /SQSTM1 synthesis. ELAVL1/HuR is a post-transcriptional factor, which acts mainly as a positive regulator of gene expression by binding to specific mRNAs, which corresponding proteins play a key role in cell functions. During proteasomal inhibition ELAVL1/HuR was up-regulated at both mRNA and protein levels, and was shown to bind with and post-transcriptionally regulate $\mathrm{p} 62 / \mathrm{SQSTM} 1 \mathrm{mRNA}$ [132]. On the other hand, substantial decreases in p62/SQSTM1 levels after proteasomal inhibition in human osteosarcoma (HOS) cells have been reported [77]. Also, after treatment of human dopaminergic neuroblastoma SH-SY5Y cells with the proteasome inhibitor lactacystin, and in dopaminergic neurons obtained from a UPS-impaired mouse model of Parkinson's disease, significantly reduced levels of p62/ /SQSTM1 were found [85]. In accordance with those data, time kinetic studies revealed that Marchantin $M$ decreased the expression of p62/SQSTM1 [87]. Interestingly, p62/SQSTM1 is itself an autophagy substrate, responsible both for the transport of polyubiquitinated protein aggregates to autophagosomes, and the promotion of their uptake to the lysosomes. It has been proposed that $\mathrm{p} 62$, even when up-regulated, is intensively degraded during process of autophagy and autophagy up-regulation causes a reduction of p62 levels [130, 133].

HDAC6 is thought to be a sensor of proteasomal inhibition and a cellular stress surveillance factor playing a key role in autophagy by controlling the fusion process of autophagosomes with lysosomes (for review see $[69,100])$. UPS inhibition leads to HDAC6 relocation and inclusion into aggresomes [134, 135]. Because HDAC6 is involved in both aggresome formation and the fusion of autophagosomes with lysosomes, HDAC6 inhibition can enhance the cytotoxicity of proteasome inhibitors [117]. The role of HDAC6 during the proteasome inhibition seems to be unrelated with its signalling to increase autophagic flux, but rather with efficient delivery of accumulated polyubiquitinated substrates for degradation (reviewed in [69]). In addition, HDAC6 may control another mechanism to facilitate cell survival, despite the inhibition of proteasome activity. Kästle et al. [136] found that after proteasome inhibition caused by lactacystin administration, the up-regulation of heat shock protein heme oxygenase-1 (HO-1) was controlled by HDAC6. They showed that under these experimental conditions, HDAC6 deacetylates p38, allowing subsequent phosphorylation of p38 and resultant activation of NRF-2, a transcription factor for HO-1 [136]. These results complement previous reports which showed that the induction of classical heat shock proteins, e.g. Hsp27 and Hsp70, required activation of HDAC6 which triggered the dissociation of HSF1 (heat-shock factor 1) from HDAC6/HSF1/ /HSP90 complex and a subsequent HSF1 activation $[137,138]$. In turn, activation of HSF1 induces the expression of newly synthesized heat shock proteins, which are necessary to prevent cellular damage caused by proteasome inhibition.

Recent studies indicate that BAG3 (Bcl-2 associated athanogene 3 ), which was previously linked with various physiological and pathological processes, including signal transduction and apoptosis [139], has been recently associated with autophagy (Figure 2), mainly of misfolded non-polyubiquitinated proteins found in aggresomes [140,141]. BAG3 belongs to the BAG co-chaperone family responsible for the regulation of the ATPase activity of the heat shock protein 70 chaperone family. A study utilizing MG-132 proteasome inhibitor showed that BAG3 interacted with Hsp70 to facilitate and selectively direct substrates to the aggresomes; additionally, this mechanism did not depend on substrate ubiquitination [140]. Treatment of rhabdomyosarcoma cells with bortezomib and ST80 (cytoplasmic histone deacetylase 6 inhibitor) up-regulated BAG3 at both mRNA and protein levels in surviving cells as well as triggered the accumulation of insoluble protein aggregates [142]. These results allowed putting forward the thesis, that BAG3 may be a novel mediator of inducible resistance to proteasome inhibition by mitigating proteotoxicity via induction of autophagy. BAG3 was also shown to be involved in proteasome inhibitor-elicited noncanonical autophagy in hepatocellular carcinoma cells, which was not suppressed by inhibitors of class III PI3K or shRNA against Beclin-1 mRNA [143].

\section{Final remarks}

Recent experimental and clinical data have shown that proteasome inhibitors serve as a new and promising class of anticancer agents [21, 24, 77, 79, 84, 87, 144]. However, the data presented in this review proved beyond doubt that proteasome inhibition induces 
autophagy in the majority of cells. The described complex network of processes leading to the activation of autophagy (Figure 2), despite being more precise than presented in reviews based on data available only a year ago, seem to be only a mere outline of complicated crosstalks between UPS and autophagy. It turns out that the two systems of protein degradation which were originally regarded as rather independent may be very closely related. According to majority of experimental data the over-activation of autophagy induces cell death and acts as a powerful tumour-supressing mechanism [35]. However, the autophagy, serving as an important mechanism to generate nutrients in time of cellular stresses, may directly contribute to the survival of cells treated with proteasome inhibitors, and consequently, may decrease the effectiveness of anti-cancer therapy [117]. Preclinical studies performed on several cancer cell types $[75,117]$ have already shown synergy between simultaneously used proteasome and autophagy inhibitors.

\section{Acknowledgement}

This work was supported by grant N N401 005735 from the Polish Ministry of Science and Higher Education. The author is highly indebt to Professor Zbigniew Kmiec, Department of Histology, Medical University of Gdansk, Poland, for critical reading of the manuscript and valuable comments and suggestions. Moreover, the author thanks Sylwia Scislowska, MA, for her graphic assistance.

\section{References}

1. Hershko A, Ciechanover A. The ubiquitin pathway for the degradation of intracellular proteins. Prog Nucleic Acid Res Mol Biol. 1986;33:19-56.

2. Pickart CM, Eddins MJ. Ubiquitin: structures, functions, mechanisms. Biochim Biophys Acta. 2004;1695:55-72.

3. Sadowski M, Sarcevic B. Mechanisms of mono- and poly -ubiquitination: Ubiquitination specificity depends on compatibility between the $\mathrm{E} 2$ catalytic core and amino acid residues proximal to the lysine. Cell Div. 2010;5:19.

4. Herrmann J, Lerman LO, Lerman A. Ubiquitin and ubiquitin-like proteins in protein regulation. Circ Res. 2007;100:1276-1291.

5. Teixeira LK, Reed SI. Ubiquitin ligases and cell cycle control. Annu Rev Biochem. 2013;82:387-414.

6. Ciechanover A. Intracellular protein degradation: from a vague idea thru the lysosome and the ubiquitin-proteasome system and onto human diseases and drug targeting. Biochim Biophys Acta. 2012;1824:3-13.

7. Crews CM. Feeding the machine: mechanisms of proteasomecatalyzed degradation of ubiquitinated proteins. Curr Opin Chem Biol. 2003;7:534-539.

8. Groll M, Ditzel L, Lowe J et al. Structure of $20 \mathrm{~S}$ proteasome from yeast at 2.4 A resolution. Nature. 1997;386:463-471.

9. Hartmann-Petersen R, Seeger M, Gordon C. Transferring substrates to the $26 \mathrm{~S}$ proteasome. Trends Biochem Sci. 2003;28:26-31.
10. McNaught KS, Olanow W. The ubiquitin-proteasome system and models of Parkinson's disease. Movement Disorders. 2004;19:S2-S3.

11. Reinstein E, Ciechanover A. Narrative review: protein degradation and human diseases: the ubiquitin connection. Ann Intern Med. 2006;145:676-684.

12. Ardley HC, Robinson PA. E3 ubiquitin ligases. Essays Biochem. 2005;41:15-30.

13. Metzger MB, Hristova VA, Weissman AM. HECT and RING finger families of E3 ubiquitin ligases at a glance. J Cell Sci. 2012;125:531-537.

14. Micel LN, Tentler JJ, Smith PG et al. Role of ubiquitin ligases and the proteasome in oncogenesis: novel targets for anticancer therapies. J Clin Oncol. 2013;31:1231-1238.

15. Kamura T, Sato S, Iwai K et al. Activation of HIF1alpha ubiquitination by a reconstituted von Hippel-Lindau (VHL) tumor suppressor complex. Proc Natl Acad Sci U S A. 2000;97:10430-10435.

16. Tanimoto K, Makino $\mathrm{Y}$, Pereira $\mathrm{T}$ et al. Mechanism of regulation of the hypoxia-inducible factor- 1 alpha by the von Hippel-Lindau tumor suppressor protein. EMBO J. 2000;19:4298-4309.

17. Peters JM, Cejka Z, Harris JR et al. Structural features of the $26 \mathrm{~S}$ proteasome complex. J Mol Biol. 1993;234:932-937.

18. Vinitsky A, Michaud C, Powers JC et al. Inhibition of the chymotrypsin-like activity of the pituitary multicatalytic proteinase complex. Biochemistry. 1992;31:9421-9428.

19. Genin E, Reboud-Ravaux M, Vidal J. Proteasome inhibitors: recent advances and new perspectives in medicinal chemistry. Curr Top Med Chem. 2010;10:232-256.

20. Pellom ST Jr., Shanker A. Development of Proteasome Inhibitors as Therapeutic Drugs. J Clin Cell Immunol. 2012;S5:5.

21. Wu WK, Cho CH, Lee CW et al. Proteasome inhibition: a new therapeutic strategy to cancer treatment. Cancer Lett. 2010;293:15-22.

22. Furet $\mathrm{P}$, Imbach $\mathrm{P}$, Noorani $\mathrm{M}$ et al. Entry into a new class of potent proteasome inhibitors having high antiproliferative activity by structure-based design. J Med Chem. 2004;47:4810-4813.

23. Lawasut $\mathrm{P}$, Chauhan $\mathrm{D}$, Laubach $\mathrm{J}$ et al. New proteasome inhibitors in myeloma. Curr Hematol Malig Rep. 2012;7:258-266.

24. Selimovic D, Porzig BB, El-Khattouti A et al. Bortezomib/ proteasome inhibitor triggers both apoptosis and autophagy-dependent pathways in melanoma cells. Cell Signal. 2013;25:308-318.

25. Teicher BA, Ara G, Herbst R et al. The proteasome inhibitor PS-341 in cancer therapy. Clin Cancer Res. 1999;5:2638-2645.

26. Groll M, Berkers CR, Ploegh HL et al. Crystal structure of the boronic acid-based proteasome inhibitor bortezomib in complex with the yeast $20 \mathrm{~S}$ proteasome. Structure. 2006; $14: 451-456$.

27. Zhang J, Wu P, Hu Y. Clinical and marketed proteasome inhibitors for cancer treatment. Curr Med Chem. 2013;20:2537-2551.

28. Qureshi AA, Guan XQ, Reis JC et al. Inhibition of nitric oxide and inflammatory cytokines in LPS-stimulated murine macrophages by resveratrol, a potent proteasome inhibitor. Lipids Health Dis. 2012;11:76.

29. Shukla Y, Singh R. Resveratrol and cellular mechanisms of cancer prevention. Ann N Y Acad Sci. 2011;1215:1-8.

30. Cherniack EP. A berry thought-provoking idea: the potential role of plant polyphenols in the treatment of age-related cognitive disorders. BrJ Nutr. 2012;108:794-800. 
31. Chen RJ, Ho CT, Wang YJ. Pterostilbene induces autophagy and apoptosis in sensitive and chemoresistant human bladder cancer cells. Mol Nutr Food Res. 2010;54:1819-1832.

32. Li J, Qin Z, Liang Z. The prosurvival role of autophagy in Resveratrol-induced cytotoxicity in human U251 glioma cells. BMC Cancer. 2009;9:215.

33. Mauthe M, Jacob A, Freiberger S et al. Resveratrol-mediated autophagy requires WIPI-1-regulated LC3 lipidation in the absence of induced phagophore formation. Autophagy. 2011;7:1448-1461.

34. Yamamoto M, Suzuki SO, Himeno M. Resveratrol-induced autophagy in human U373 glioma cells. Oncol Lett. 2010;1:489-493.

35. Mizushima N, Levine B, Cuervo AM, Klionsky DJ. Autophagy fights disease through cellular self-digestion. Nature. 2008;451:1069-1075.

36. Todde V, Veenhuis M, van der Klei IJ. Autophagy: principles and significance in health and disease. Biochim Biophys Acta. 2009;1792:3-13.

37. Tooze SA, Schiavo G. Liaisons dangereuses: autophagy, neuronal survival and neurodegeneration. Curr Opin Neurobiol. 2008;18:504-515.

38. Grotemeier A, Alers S, Pfisterer SG et al. AMPK-independent induction of autophagy by cytosolic $\mathrm{Ca} 2+$ increase. Cell Signal. 2010;22:914-925.

39. Jung $\mathrm{CH}$, Ro SH, Cao J et al. mTOR regulation of autophagy. FEBS Lett. 2010;584:1287-1295.

40. Whitney ML, Jefferson LS, Kimball SR. ATF4 is necessary and sufficient for ER stress-induced upregulation of REDD1 expression. Biochem Biophys Res Commun. 2009;379:451-455.

41. Hara K, Maruki Y, Long X et al. Raptor, a binding partner of target of rapamycin (TOR), mediates TOR action. Cell. 2002;110:177-189.

42. Vander Haar E, Lee SI, Bandhakavi S et al. Insulin signalling to mTOR mediated by the Akt/PKB substrate PRAS40. Nat Cell Biol. 2007;9:316-323.

43. Zhao J, Brault JJ, Schild A et al. FoxO3 coordinately activates protein degradation by the autophagic/lysosomal and proteasomal pathways in atrophying muscle cells. Cell MeTable. 2007;6:472-483.

44. Pearce LR, Huang X, Boudeau J et al. Identification of Protor as a novel Rictor-binding component of mTOR complex-2. Biochem J. 2007;405:513-522.

45. Sarbassov DD, Ali SM, Kim DH et al. Rictor, a novel binding partner of mTOR, defines a rapamycin-insensitive and raptor-independent pathway that regulates the cytoskeleton. Curr Biol. 2004;14:1296-1302.

46. Jacinto E, Facchinetti V, Liu D et al. SIN1/MIP1 maintains rictor-mTOR complex integrity and regulates Akt phosphorylation and substrate specificity. Cell. 2006;127:125-137.

47. Oh WJ, Jacinto E. mTOR complex 2 signaling and functions. Cell Cycle. 2011;10:2305-2316.

48. Polson HE, de Lartigue J, Rigden DJ et al. Mammalian Atg18 (WIPI2) localizes to omegasome-anchored phagophores and positively regulates LC3 lipidation. Autophagy. 2010;6:506-522.

49. Korolchuk VI, Menzies FM, Rubinsztein DC. Mechanisms of cross-talk between the ubiquitin-proteasome and autophagy -lysosome systems. FEBS Lett. 2010;584:1393-1398.

50. Mizushima N. The role of the Atg1/ULK1 complex in autophagy regulation. Curr Opin Cell Biol. 2010;22:132-139.

51. Liang C, Feng P, Ku B et al. UVRAG: a new player in autophagy and tumor cell growth. Autophagy. 2007;3:69-71.

52. Kihara A, Noda $\mathrm{T}$, Ishihara $\mathrm{N}$ et al. Two distinct Vps 34 phosphatidylinositol 3-kinase complexes function in autophagy and carboxypeptidase Y sorting in Saccharomyces cerevisiae. J Cell Biol. 2001;152:519-530.

53. Webber JL, Tooze SA. New insights into the function of Atg9. FEBS Lett. 2010;584:1319-1326.
54. Nazio F, Cecconi F. mTOR, AMBRA1, and autophagy: an intricate relationship. Cell Cycle. 2013;12:2524-2525.

55. Hara T, Takamura A, Kishi C et al. FIP200, a ULK-interacting protein, is required for autophagosome formation in mammalian cells. J Cell Biol. 2008;181:497-510.

56. Tanida I. Autophagy basics. Microbiol Immunol. 2011;55:1-11.

57. Hosokawa N, Sasaki T, Iemura S et al. Atg101, a novel mammalian autophagy protein interacting with Atg13. Autophagy. 2009;5:973-979.

58. Hosokawa N, Hara T, Kaizuka T et al. Nutrient-dependent mTORC1 association with the ULK1-Atg13-FIP200 complex required for autophagy. Mol Biol Cell. 2009;20:1981-1991.

59. Koren I, Reem E, Kimchi A. DAP1, a novel substrate of mTOR, negatively regulates autophagy. Curr Biol. 2010;20:1093-1098.

60. Kabeya Y, Mizushima N, Ueno T et al. LC3, a mammalian homologue of yeast Apg8p, is localized in autophagosome membranes after processing. EMBO J. 2000;19:5720-5728.

61. von Muhlinen N, Akutsu M, Ravenhill BJ et al. LC3C, bound selectively by a noncanonical LIR motif in NDP52, is required for antibacterial autophagy. Mol Cell. 2012;48:329-342.

62. Czyzyk-Krzeska MF, Meller J, Plas DR. Not all autophagy is equal. Autophagy. 2012;8:1155-1156.

63. Mikhaylova O, Stratton Y, Hall D et al. VHL-regulated MiR-204 suppresses tumor growth through inhibition of LC3B-mediated autophagy in renal clear cell carcinoma. Cancer Cell. 2012;21:532-546.

64. Dall'Armi C, Devereaux KA, Di Paolo G. The role of lipids in the control of autophagy. Curr Biol. 2013;23:R33-45.

65. Ganley IG. Autophagosome maturation and lysosomal fusion. Essays Biochem. 2013;55:65-78.

66. Wilde IB, Brack M, Winget JM et al. Proteomic characterization of aggregating proteins after the inhibition of the ubiquitin proteasome system. J Proteome Res. 2011;10:10621072.

67. Komatsu M, Waguri S, Koike M et al. Homeostatic levels of p62 control cytoplasmic inclusion body formation in autophagy-deficient mice. Cell. 2007;131:1149-1163.

68. Gao Z, Gammoh N, Wong PM et al. Processing of autophagic protein LC3 by the 20 S proteasome. Autophagy. 2010;6:126-137.

69. Richter-Landsberg C, Leyk J. Inclusion body formation, macroautophagy, and the role of HDAC6 in neurodegeneration. Acta Neuropathol. 2013;126:793-807.

70. Yan J, Seibenhener ML, Calderilla-Barbosa Let al. SQSTM1/ p62 Interacts with HDAC6 and Regulates Deacetylase Activity. PLoS One. 2013;8:e76016.

71. Inoue M, Zhai H, Sakazaki H et al. TMC-95A, a reversible proteasome inhibitor, induces neurite outgrowth in $\mathrm{PC} 12$ cells. Bioorg Med Chem Lett. 2004;14:663-665.

72. Stauch B, Simon B, Basile T et al. Elucidation of the structure and intermolecular interactions of a reversible cyclic-peptide inhibitor of the proteasome by NMR spectroscopy and molecular modeling. Angew Chem Int Ed Engl. 2010;49:3934-3938.

73. Yang H, Landis-Piwowar KR, Chen D et al. Natural compounds with proteasome inhibitory activity for cancer prevention and treatment. Curr Protein Pept Sci. 2008;9:227-239.

74. Zhang X, Li W, Wang Cet al. Inhibition of autophagy enhances apoptosis induced by proteasome inhibitor bortezomib in human glioblastoma U87 and U251 cells. Mol Cell Biochem. 2014;385:265-275.

75. Ding WX, Ni HM, Gao W et al. Linking of autophagy to ubiquitin-proteasome system is important for the regulation of endoplasmic reticulum stress and cell viability. Am J Pathol. 2007:171:513-524. 
76. Li C, Johnson DE. Bortezomib induces autophagy in head and neck squamous cell carcinoma cells via JNK activation. Cancer Lett. 2012;314:102-107.

77. Lou Z, Ren T, Peng X et al. Bortezomib induces apoptosis and autophagy in osteosarcoma cells through mitogen-activated protein kinase pathway in vitro. J Int Med Res. 2013;41:1505-1519.

78. Zhang HY, Du ZX, Meng X et al. Beclin 1 enhances proteasome inhibition-mediated cytotoxicity of thyroid cancer cells in macroautophagy-independent manner. J Clin Endocrinol MeTable. 2013;98:E217-226.

79. Wu WK, Wu YC, Yu L et al. Induction of autophagy by proteasome inhibitor is associated with proliferative arrest in colon cancer cells. Biochem Biophys Res Commun. 2008;374:258-263.

80. Wu WK, Volta V, Cho $\mathrm{CH}$ et al. Repression of protein translation and mTOR signaling by proteasome inhibitor in colon cancer cells. Biochem Biophys Res Commun. 2009;386:598-601.

81. Wu WK, Cho CH, Lee CW et al. Macroautophagy and ERK phosphorylation counteract the antiproliferative effect of proteasome inhibitor in gastric cancer cells. Autophagy. 2010;6:228-238.

82. Shen D, Coleman J, Chan E et al. Novel cell- and tissue-based assays for detecting misfolded and aggregated protein accumulation within aggresomes and inclusion bodies. Cell Biochem Biophys. 2011;60:173-185.

83. Xiong R, Siegel D, Ross D. The activation sequence of cellular protein handling systems after proteasomal inhibition in dopaminergic cells. Chem Biol Interact. 2013;204:116-124.

84. Zhu K, Dunner K, Jr., McConkey DJ. Proteasome inhibitors activate autophagy as a cytoprotective response in human prostate cancer cells. Oncogene. 2010;29:451-462.

85. Shen YF, Tang Y, Zhang XJ et al. Adaptive changes in autophagy after UPS impairment in Parkinson's disease. Acta Pharmacol Sin. 2013;34:667-673.

86. Gimenez-Xavier P, Francisco R, Santidrian AF et al. Effects of dopamine on LC3-II activation as a marker of autophagy in a neuroblastoma cell model. Neurotoxicology. 2009;30:658-665.

87. Jiang H, Sun J, Xu Q et al. Marchantin M: a novel inhibitor of proteasome induces autophagic cell death in prostate cancer cells. Cell Death Dis. 2013;4:e761.

88. Filippi-Chiela EC, Villodre ES, Zamin LL et al. Autophagy interplay with apoptosis and cell cycle regulation in the growth inhibiting effect of resveratrol in glioma cells. PLoS One. 2011;6:e20849.

89. Chakraborty A, Bodipati N, Demonacos MK et al. Long term induction by pterostilbene results in autophagy and cellular differentiation in MCF-7 cells via ROS dependent pathway. Mol Cell Endocrinol. 2012;355:25-40.

90. Wang Y, Ding L, Wang X et al. Pterostilbene simultaneously induces apoptosis, cell cycle arrest and cyto-protective autophagy in breast cancer cells. Am J Transl Res. 2012;4:44-51.

91. Hsieh MJ, Lin CW, Yang SF et al. A combination of pterostilbene with autophagy inhibitors exerts efficient apoptotic characteristics in both chemosensitive and chemoresistant lung cancer cells. Toxicol Sci. 2014;137:65-75.

92. Siedlecka-Kroplewska K, Jozwik A, Boguslawski W et al. Pterostilbene induces accumulation of autophagic vacuoles followed by cell death in HL60 human leukemia cells.J Physiol Pharmacol. 2013;64:545-556.

93. Tanida I, Ueno T, Kominami E. LC3 and Autophagy. Methods Mol Biol. 2008;445:77-88.
94. Ni HM, Bockus A, Wozniak AL et al. Dissecting the dynamic turnover of GFP-LC3 in the autolysosome. Autophagy. 2011;7:188-204.

95. Belloni D, Veschini L, Foglieni C et al. Bortezomib induces autophagic death in proliferating human endothelial cells. Exp Cell Res. 2010;316:1010-1018.

96. Archer CR, Koomoa DL, Mitsunaga EM et al. Syrbactin class proteasome inhibitor-induced apoptosis and autophagy occurs in association with $\mathrm{p} 53$ accumulation and $\mathrm{Akt} / \mathrm{PKB}$ activation in neuroblastoma. Biochem Pharmacol. 2010;80:170-178.

97. Klappan AK, Hones S, Mylonas I et al. Proteasome inhibition by quercetin triggers macroautophagy and blocks mTOR activity. Histochem Cell Biol. 2012;137:25-36.

98. Williams JA, Hou Y, Ni HM et al. Role of intracellular calcium in proteasome inhibitor-induced endoplasmic reticulum stress, autophagy, and cell death. Pharm Res. 2013;30:2279-2289.

99. Back JH, Zhu Y, Calabro A et al. Resveratrol-mediated downregulation of Rictor attenuates autophagic process and suppresses UV-induced skin carcinogenesis. Photochem Photobiol. 2012;88:1165-1172.

100. Wu WK, Sakamoto KM, Milani M et al. Macroautophagy modulates cellular response to proteasome inhibitors in cancer therapy. Drug Resist Updat. 2010;13:87-92.

101. Davies C, Tournier C. Exploring the function of the JNK (c-Jun N-terminal kinase) signalling pathway in physiological and pathological processes to design novel therapeutic strategies. Biochem Soc Trans. 2012;40:85-89.

102. Sabapathy K. Role of the JNK pathway in human diseases. Prog Mol Biol Transl Sci. 2012;106:145-169.

103. Kim R, Emi M, Tanabe K et al. Role of the unfolded protein response in cell death. Apoptosis. 2006;11:5-13.

104. Pavitt GD, Ron D. New insights into translational regulation in the endoplasmic reticulum unfolded protein response. Cold Spring Harb Perspect Biol. 2012;4:a012278.

105. Wei Y, Pattingre S, Sinha S et al. JNK1-mediated phosphorylation of Bcl-2 regulates starvation-induced autophagy. $\mathrm{Mol}$ Cell. 2008;30:678-688.

106. You SA, Basu A, Haldar S. Potent antitumor agent proteasome inhibitors: a novel trigger for Bcl 2 phosphorylation to induce apoptosis. Int J Oncol. 1999;15:625-628.

107. Basu A, Haldar S. Signal-induced site specific phosphorylation targets $\mathrm{Bcl} 2$ to the proteasome pathway. Int J Oncol. 2002;21:597-601.

108. Jiang HY, Wek RC. Phosphorylation of the alpha-subunit of the eukaryotic initiation factor-2 (eIF2alpha) reduces protein synthesis and enhances apoptosis in response to proteasome inhibition. J Biol Chem. 2005;280:14189-14202.

109. Acharya P, Engel JC, Correia MA. Hepatic CYP3A suppression by high concentrations of proteasomal inhibitors: a consequence of endoplasmic reticulum (ER) stress induction, activation of RNA-dependent protein kinase-like ER-bound eukaryotic initiation factor 2alpha (eIF2alpha)-kinase (PERK) and general control nonderepressible-2 eIF2alpha kinase (GCN2), and global translational shutoff. Mol Pharmacol. 2009;76:503-515.

110. Gavilan MP, Pintado C, Gavilan E et al. Dysfunction of the unfolded protein response increases neurodegeneration in aged rat hippocampus following proteasome inhibition. Aging Cell. 2009;8:654-665.

111. Rouschop KM, van den Beucken T, Dubois L et al. The unfolded protein response protects human tumor cells during hypoxia through regulation of the autophagy genes MAP1LC3B and ATG5. J Clin Invest. 2010;120:127-141.

112. Cusimano A, Azzolina A, Iovanna JL et al. Novel combination of celecoxib and proteasome inhibitor MG132 provides 
synergistic antiproliferative and proapoptotic effects in human liver tumor cells. Cell Cycle. 2010;9:1399-1410.

113. Hu J, Dang N, Menu E et al. Activation of ATF4 mediates unwanted Mcl-1 accumulation by proteasome inhibition. Blood. 2012;119:826-837.

114. Bardag-Gorce F. Proteasome inhibitor treatment in alcoholic liver disease. World J Gastroenterol. 2011;17:2558-2562.

115. Ohta K, Mizuno A, Ueda M et al. Autophagy impairment stimulates PS1 expression and gamma-secretase activity. Autophagy. 2010;6:345-352.

116. Suzuki T, Osumi N, Wakamatsu Y. Stabilization of ATF4 protein is required for the regulation of epithelial-mesenchymal transition of the avian neural crest. Dev Biol. 2010;344:658-668.

117. Milani M, Rzymski T, Mellor HR et al. The role of ATF4 stabilization and autophagy in resistance of breast cancer cells treated with Bortezomib. Cancer Res. 2009;69:4415-4423.

118. Lassot I, Segeral E, Berlioz-Torrent C et al. ATF4 degradation relies on a phosphorylation-dependent interaction with the SCF(betaTrCP) ubiquitin ligase. Mol Cell Biol. 2001;21:2192-2202.

119. Martelli AM, Evangelisti C, Chiarini F et al. The phosphatidylinositol 3-kinase/Akt/mTOR signaling network as a therapeutic target in acute myelogenous leukemia patients. Oncotarget. 2010;1:89-103.

120. Ikenoue T, Hong S, Inoki K. Monitoring mammalian target of rapamycin (mTOR) activity. Methods Enzymol. 2009;452:165-180.

121. Ghosh $\mathrm{P}, \mathrm{Wu} \mathrm{M}, \mathrm{Zhang} \mathrm{H}$ et al. mTORC1 signaling requires proteasomal function and the involvement of CUL4-DDB1 ubiquitin E3 ligase. Cell Cycle. 2008;7:373-381.

122. Bruning A, Rahmeh M, Friese K. Nelfinavir and bortezomib inhibit mTOR activity via ATF4-mediated sestrin-2 regulation. Mol Oncol. 2013;7:1012-1018.

123. Ben-Sahra I, Dirat B, Laurent K et al. Sestrin2 integrates Akt and mTOR signaling to protect cells against energetic stress-induced death. Cell Death Differ. 2013;20:611-619.

124. Maiuri MC, Malik SA, Morselli E et al. Stimulation of autophagy by the p53 target gene Sestrin2. Cell Cycle. 2009;8:1571-1576.

125. Lun M, Zhang PL, Siegelmann-Danieli N et al. Intracellular inhibitory effects of Velcade correlate with morphoproteomic expression of phosphorylated-nuclear factor-kappaB and p53 in breast cancer cell lines. Ann Clin Lab Sci. 2005;35:15-24.

126. Du Y, Yang D, Li L et al. An insight into the mechanistic role of p53-mediated autophagy induction in response to proteasomal inhibition-induced neurotoxicity. Autophagy. 2009;5:663-675.

127. Zhang XY, Wu XQ, Deng R et al. Upregulation of sestrin 2 expression via JNK pathway activation contributes to autophagy induction in cancer cells. Cell Signal. 2013;25:150-158.

128. Zhang L, Cui L, Zhou G et al. Pterostilbene, a natural small-molecular compound, promotes cytoprotective ma- croautophagy in vascular endothelial cells. J Nutr Biochem. 2013;24:903-911.

129. Kopito RR. Aggresomes, inclusion bodies and protein aggregation. Trends Cell Biol. 2000;10:524-530.

130. Kuusisto E, Suuronen T, Salminen A. Ubiquitin-binding protein p62 expression is induced during apoptosis and proteasomal inhibition in neuronal cells. Biochem Biophys Res Commun. 2001;280:223-228.

131. Myeku N, Figueiredo-Pereira ME. Dynamics of the degradation of ubiquitinated proteins by proteasomes and autophagy: association with sequestosome 1/p62. J Biol Chem. 2011;286:22426-22440.

132. Viiri J, Amadio M, Marchesi N et al. Autophagy activation clears ELAVL1/HuR-mediated accumulation of SQSTM1/ p62 during proteasomal inhibition in human retinal pigment epithelial cells. PLoS One. 2013;8:e69563.

133. Jaakkola PM, Pursiheimo JP. p62 degradation by autophagy: another way for cancer cells to survive under hypoxia. Autophagy. 2009;5:410-412.

134. Kawaguchi Y, Kovacs JJ, McLaurin A et al. The deacetylase HDAC6 regulates aggresome formation and cell viability in response to misfolded protein stress. Cell. 2003;115:727-738.

135. Pandey UB, Nie Z, Batlevi Y et al. HDAC6 rescues neurodegeneration and provides an essential link between autophagy and the UPS. Nature. 2007;447:859-863.

136. Kastle M, Woschee E, Grune T. Histone deacetylase 6 (HDAC6) plays a crucial role in p38MAPK-dependent induction of heme oxygenase-1 (HO-1) in response to proteasome inhibition. Free Radic Biol Med. 2012;53:2092-2101.

137. Anckar J, Sistonen L. Regulation of HSF1 function in the heat stress response: implications in aging and disease. Annu Rev Biochem. 2011;80:1089-1115.

138. Boyault C, Zhang Y, Fritah S et al. HDAC6 controls major cell response pathways to cytotoxic accumulation of protein aggregates. Genes Dev. 2007;21:2172-2181.

139. Bonelli P, Petrella A, Rosati A et al. BAG3 protein regulates stress-induced apoptosis in normal and neoplastic leukocytes. Leukemia. 2004;18:358-360.

140. Gamerdinger M, Kaya AM, Wolfrum U et al. BAG3 mediates chaperone-based aggresome-targeting and selective autophagy of misfolded proteins. EMBO Rep. 2011;12:149-156.

141. Behl C. BAG3 and friends: co-chaperones in selective autophagy during aging and disease. Autophagy. 2011;7:795-798.

142. Rapino F, Jung M, Fulda S. BAG3 induction is required to mitigate proteotoxicity via selective autophagy following inhibition of constitutive protein degradation pathways. Oncogene. 2013. DOI:10.1038/onc.2013.110. [Epub ahead of print].

143. Liu BQ, Du ZX, Zong ZH et al. BAG3-dependent noncanonical autophagy induced by proteasome inhibition in HepG2 cells. Autophagy. 2013;9:905-916.

144. Sakairi T, Hiromura K, Takahashi S et al. Effects of proteasome inhibitors on rat renal fibrosis in vitro and in vivo. Nephrology (Carlton). 2011;16:76-86. 